\title{
Analisis Pelayanan Terhadap Tingkat Kepuasan Mahasiswa Fakultas Ekonomi Universitas Batanghari Jambi (Studi pada Laboratorium Statistik Fakultas Ekonomi Universitas Batanghari Jambi)
}

\author{
Albetris, Fadil Iskandar \\ Fakultas Ekonomi Universitas Batanghari Jambi \\ Corresponding email : albetris90@gmail.com
}

\begin{abstract}
Abstrak_Penelitian ini bertujuan untuk untuk mengetahui bagaimana Pengaruh Pelayanan Terhadap Kepuasan Mahasiswa di Fakultas Ekonomi Universitas Batanghari Jambi. Batasan masalah dalam penelitian ini adalah sebagai berikut: 1 . Variabel yang digunakan dalam penelitian ini adalah variable kualitas pelayanan yang meliputi responsiveness (daya tanggap), reliability (keandalan), assurance (jaminan), emphaty (empati), tangibles (bukti langsung). Dan 2. Gap yang digunakan pada penelitian ini adalah kesenjangan antara kualitas pelayanan yang dipersepsikan dengan kualitas layanan yang diharapkan (service quality gap). Penelitian ini dianalisis dengan menggunakan regresi linier berganda.dengan hasil $\mathrm{Y}=0,441+0,860 \mathrm{X}$. Dengan kata lain persamaan regresi tersebut diatas dapat dikatakan bahwa koefesien regresi variabel pelayanan mempunyai arah yang positif terhadap kepuasan mahasiswa fakultas ekonomi universitas batanghari jambi. Nilai konstanta atau $\alpha$ sebesar 0,441 artinya jika nilai variabel X (pelayanan) bernilai 0 maka nilai variabel Y (kepuasan) akan bernilai sebesar 0,441. Nilai koefesien (b) sebesar 0,860 artinya nilai variabel X (pelayanan) bernilai positif artinya jika variabel pelayanan (X1) naik sebesar 1 satuan maka akan meningkatkan variabel Y (kepuasan) sebesar 0,860 dengan asumsi variabel lainnya tetap.dan berdasarkan uji statistik diketahui bahwa terdapat pengaruh signifikan antara pelayanan terhadap kepuasan pengguna jasa ( mahasiswa ) laboratorium komputer Fakultas Ekonomi Universitas Batanghari Jambi, dengan menggunakan uji $\mathrm{t}$ yaitu, $\mathrm{t}_{\text {hitung }}=26.106>\mathrm{t}_{\text {tabel }}=1,984$.
\end{abstract}

Kata Kunci: analisis pelayanan; tingkat kepuasan; laboratorium statistik

\begin{abstract}
This research aims to find out how the Service Affects Student Satisfaction at the Faculty of Economics, Batanghari Jambi University. The limitations of the problems in this study are as follows: 1. The variables used in this study are service quality variables that include responsiveness, reliability, assurance, emphaty (empathy), tangibles (direct evidence). And 2. The gap used in this study is the gap between the quality of service perceived and the expected quality of service (service quality gap). The study was analyzed using multiple linear regressions. with results $Y=0.441+0.860 X$. In other words, the regression equation above can be said that the coeffesien regression variable service has a positive direction towards the satisfaction of students of the faculty of economics of batanghari jambi university. The constant or $\alpha$ value of 0.441 means that if the value of variable $X$ (service) is 0 then the variable value $Y$ (satisfaction) will be worth 0.441 . The coefficient value (b) of 0.860 means that the value of variable $X$ (service) is positive meaning that if the service variable (X1) rises by 1 unit it will increase variable $Y$ (satisfaction) by 0.860 assuming other variablesits same. and based on statistical tests it is known that there is a significant influence between the service on the satisfaction of service users ( students) computer laboratory of the Faculty of Economics, Batanghari Jambi University, using the t test that is, thitung $=26,106>$ t table $=1,984$.
\end{abstract}

Keywords: service analysis; satisfaction level; laboratory statistics

\section{PENDAHULUAN}

Pelaksanaan evaluasi pembelajaran menekankan pada evaluasi proses pembelajaran dan evaluasi hasil belajar. Kedua jenis evaluasi tersebut merupakan komponen sistem pembelajaran yang sangat penting yang dapat dipergunakan untuk mengetahui kekuatan dan kelemahan pelaksanaan dan hasil pembelajaran. Selanjutnya digunakan sebagai bahan dan dasar peningkatan kualitas proses pembelajaran menuju ke perbaikan kualitas hasil pembelajaran (Tim Pekerti-AA, 2007: 6). Kualitas pembelajaran berfokus pada upaya pemenuhan kebutuhan dan harapan mahasiswa.

Mahasiswa merupakan pelanggan internal akademik dan administratif dalam lingkungan pendidikan tinggi. Tingkat kepuasan yang diukur untuk mengetahu i kualitas pembelajaran adalah tingkat kepuasan mahasiswa. Kepuasan dimaksudkan sebagai pemenuhan kebutuhan dan harapan mahasiswa sebagai pelanggan pelayanan jasa pendidikan (Margono, 2005:9).
Penilaian tingkat kepuasan mahasiswa yang merupakan salah satu aspek penilaian terhadap kualitas pelayanan pendidikan, memiliki arti penting bagi kelangsungan sistem pendidikan. Hasil penilaian tingkat kepuasan mahasiswa dapat digunakan untuk mengarahkan sistem pendidikan yang lebih baik (Widarti, dkk, 2008:163). Universitas sebagai suatu institusi perguruan tinggi swasta perlu mengedepankan aspek layanan terhadap mahasiswa.

\section{Manajemen}

Perencanaan, pengorganisasian, dan penggunaan sumber daya organisasi yang lain dalam rangka mencapai tujuan organisasi yang telah di tetapkan.

\section{Kepuasan Pelanggan (Customer Satisfaction)}

Kemampuan perusahaan untuk dapat mengenali, memenuhi dan memuaskan kebutuhan pelanggan dengan baik, merupakan strategi pada setiap perusahaaan. 
Kepuasan pelanggan telah menjadi konsep sentral dalam wacana bisnis.

Menurut Anderson dalam International Journal of Scientific \& Technology Research (Khan, 2012) kepuasan pelanggan digunakan untuk mengukur kinerja perusahaan di kedua internal untuk mengkompensasi sumber daya manusia, mengamati kinerja dan menetapkan dana serta untuk kepuasan pelanggan eksternal juga sebagai sumber informasi bagi semua pemangku kepentingan (pelanggan, kebijakan publik yang dibuat pesaing dan investor)

Menurut Tjiptono $(2005 ; 210)$ ada empat metode yang dilakukan perusahaan untuk menegetahui tingkat kepuasan pelanggan, yaitu:

a. Sistem Keluhan dan Saran

b. Ghost Shopping (Pembelanjaan Misteri)

c. Lost Customer Analysis (Analisis Pelanggan yang Berhenti)

d. Survey Kepuasan Pelanggan

Fandy Tjiptono (2011: 433) "Kepuasan merupakan evaluasi purnabeli keseluruhan yang membandingkan persepsi kinerja produk dengan ekspektasi pra pembelian". Mowen (1995) dalam Fandy Tjiptono, merumuskan "Kepuasan pelanggan sebagai sikap keseluruhan terhadap suatu barang atau jasa setelah perolehan (acquisition) dan pemakaiannya" (2011: 434). Dengan kata lain, kepuasan pelanggan merupakan penilaian evaluatif purnabeli yang dihasilkan dari seleksi spesifik.

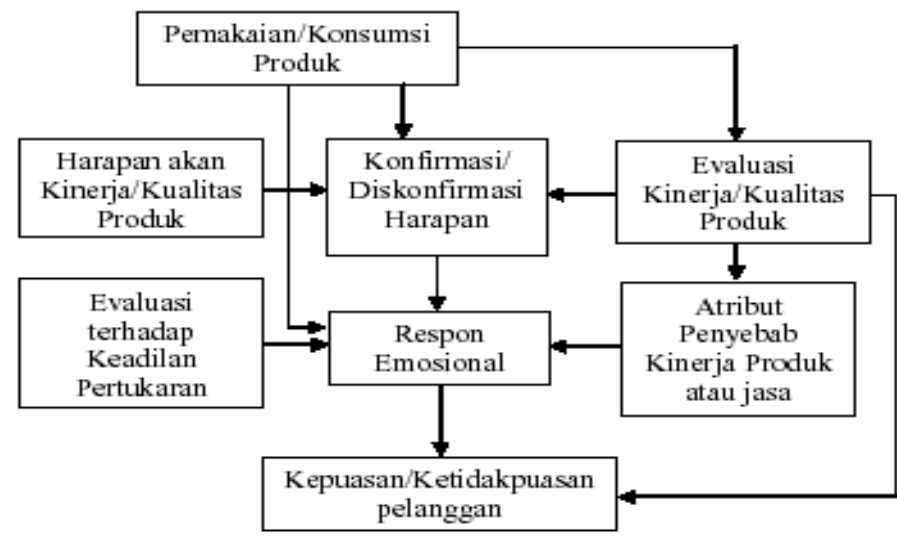

Sumber: Fandy Tjiptono (2011: 435)

Gambar 1. ModelKepuasan/Ketidakpuasan Pelanggan

kepuasan pelanggan adalah respon (baik respon emosional maupun kognitif) atau penilaian dari evaluasi yang dilakukan oleh pelanggan dengan membandingkan persepsi terhadap kinerja/kualitas produk dengan harapan yang akan diterimanya bila ia membeli atau mengkonsumsi suatu produk atau jasa.

a. Price (Harga)

b. Service Quality (Kualitas Layanan)

c. Product Quality ( Kualitas Produk)

d. Emotional Factor( Faktor Emosi)

e. Efficiency (Kemudahan)
Berikut strategi kepuasan pelanggan yang dapat diterapkan pada perusahaan jasa menurut Tjiptono (2005; 216):

a. Strategi Manajemen Ekspektasi Pelanggan

b. Relasi Pemasaran dan Manajemen

c. After Marketing (Setelah Pemasaran)

d. Strategi Retensi Pelanggan

e. Pelayanan Pelanggan Superior

f. Strategi Pemasukan atau Infusi Teknologi

g. Sistem Penanganan Komplain secara Efektif

h. Strategi Pemulihan Layanan

\section{Manfaat Kepuasan Pelanggan}

Menurut Tjiptono (2005: 140) ada beberapa manfaat jika perusahaan dapat memaksimalkan tingkat kepuasan pelanggannya, antara lain adalah:

a. Terjalin relasi hubungan jangka panjang antara perusahaan dan para pelanggannya.

b. Terbentuknya peluang pertumbuhan bisnis melalui pembelian ulang, cross-selling dan up-selling.

c. Terciptanya loyalitas pelanggan.

d. Terjadinya rekomendasi dari mulut ke mulut yang positif, berpotensi menarik pelanggan baru dan menguntungkan bagi perusahaan.

e. Reputasi perusahaan dan persepsi pelanggan semakin positif di mata pelanggan.

f. Laba yang diproleh perusahaan dapat meningkat.

\section{Kepercayaan Pelanggan (Customer Trust)}

Kepercayaan ini tidak begitu saja diakui oleh mitra bisnis/pihak lain, melainkan harus dibangun dari awal dan dapat dibuktikan.

Menurut Mayer et al. dalam International Journal of Business and Management (Danesh, Nasab dan Ling, 2012) kepercayaan didefinisikan sebagai kesediaan pihak lain untuk menjadi rentan terhadap tindakan pihak lain didasarkan pada harapan bahwa yang lain akan melakukan tindakan tertentu yang penting untuk kepercayaan tersebut, terlepas dari kemampuan untuk memonitor atau mengendalikan pihak lain.

Faktor yang membentuk kepercayaan seseorang terhadap yang lain ada tiga menurut Mayer et al. (Rofiq, 2007) :

a. Ability (Kemampuan)

b. Benevolence (Kebaikan Hati)

c. Integrity (Integritas)

Menurut Hoffman dan Bateson (2006) strategi untuk membangun kepercayaan secara umum antara lain:

a. Perlindungan informasi yang rahasia.

b. Menahan diri untuk tidak membuat komentar yang meremehkan tentang pelanggan dan pesaing lainnya.

c. Memberikan informasi kepada pelanggan yang sebenarnya, walaupun itu sangat menyakitkan.

d. Menyediakan pelanggan dengan informasi yang penuh baik secara pro dan kontra.

e. Menjadi perusahaan yang bisa diandalkan, sopan, dan penuh perhatian kepada pelanggan. 
f. Aktif dan terlibat dalam urusan masyarakat.

\section{Retensi Pelanggan}

Retensi pelanggan merupakan salah satu indikator yang paling penting dari kepuasan pelanggan. Kepuasan pelanggan secara tradisional telah dianggap sebagai penentu mendasar jangka panjang perilaku pelanggan.

Menurut Rust et al dalam International Journal of Scientific \& Technology Research (Khan, 2012) retensi pelanggan dan daya tarik pelanggan baru digunakan sebagai driver untuk peningkatan pangsa pasar dan pendapatan.

Menurut Kotler (2002: 197) ada 3 dimensi untuk membangun Retensi Pelanggan:

a. Financial Benefits (Manfaat Sosial)

b. Social Benefits (Manfaat Sosial)

c. Structural Ties (Ikatan Struktural)

Strategi retensi pelanggan difokuskan pada teknik - teknik yang digunakan untuk mempertahankan pelanggan agar pelanggan tidak beralih pada pemasok atau perusahan jasa yang lain. Menurut Tjiptono (2005; 227) ada enam faktor yang merupakan manfaat ekonomik dalam mempertahankan pelanggan;
a. Biaya Akuisisi Pelanggan Baru
b. Profit Dasar
c. Pertumbuhan Pendapatan
d. Penghematan Biaya
e. Referrals
f. Harga Premium.

\section{Hipotesis} berikut :

Maka hipotesis dalam penelian ini adalah sebagai

Ho = Pelayanan tidak berpengaruh secara signifikan terhadap Kepuasan Mahasiswa

Fakultas Ekonomi Universitas Batangahri.

$\mathrm{H} 1$ = Pealayanan berpengaruh secara signifikan

terhadap Kepuasan Mahasiswa Fakultas

Ekonomi Universitas Batangahri.

\section{METODE}

\section{Jenis dan Sumber Data}

Data yang digunakan pada penelitian ini adalah data primer dan data sekunder. Waktu penelitian dimulai dari bulan Februari sampai bulan Maret 2020

\section{Metode Pengumpulan Data}

Teknik pengumpulan data yang digunakan dalam penelitian ini adalah sebagai berikut:

a. Kuesioner.

b. Studi Pustaka (Library Research).

\section{Populasi dan Sampel}

Adapun populasi dan sampel dalam penelitian ini adalah Seluruh Calon Wisudawan Fakultas Ekonomi Universitas Batanghari ke 47 Tahun 2020.

\section{Metode Analisis Data}

Dalam penelitian ini penulis akan menganalisis data yang diperoleh secara Deskriptif Kualitatif dan Kuantitatif.

\section{HASIL DAN PEMBAHASAN}

Metode pengumpulan data dilakukan dengan cara menyebarkan kuesioner kepada seluruh mahasoiswa calon wisudawan Fakultas ekonomi universitas Batanghari yang berjumlah. Kuesioner ini di sebarkan langsung kepada responden yang pernah mengikuti pengolahan data di laboratorium statistik fakultas ekonomi universitas Batanghari jambi.

\section{Karakteristik Responden}

Tabel 1. Karakteristik responden menurut jenis kelamin Jenis kelamin Jumlah Persentase

\begin{tabular}{ccc} 
& & $(\%)$ \\
\hline PEREMPUAN & 52 & 52 \\
Laki - laki & 48 & 48 \\
Jumlah & 100 & 100 \\
\hline data primer (diolah ), tahun 2020
\end{tabular}

Sumber : data primer (diolah ), tahun 2020

Pengaruh pelayanan terhadap tingkat kepuasan mahasiswa fakultas ekonomi universitas batanghari jambi

\section{Persamaan regresi}

pengaruh pelayanan terhadap tingkat kepuasan mahasiswa fakultas ekonomi universitas batanghari jambi berdasarkan perhitungan SPSS 20 dapat dilihat sebagai berikut :

Tabel 2. Analisis Regresi Berganda Coefficients $^{\mathbf{a}}$

\begin{tabular}{lllllrr}
\hline & & \multicolumn{2}{c}{ Unstandardized Coefficients } & \multicolumn{2}{c}{ Standardized Coefficients } & \\
Model & B & Std. Error & Beta & T & Sig. \\
\hline 1 & (Constant) &, 441 &, 105 & & 4,187 &, 000 \\
& Pelayanan &, 860 &, 033 &, 935 & 26,106 &, 000 \\
\hline
\end{tabular}

a. Dependent Variable: kepuasan

Berdasarkan Regresi Linear Berganda : $\mathrm{Y}=0,441$ $+0,860 X$. Dengan kata lain persamaan regresi tersebut diatas dapat dikatakan bahwa koefesien regresi variabel pelayanan mempunyai arah yang positif terhadap kepuasan mahasiswa fakultas ekonomi universitas batanghari jambi. Nilai konstanta atau $\alpha$ sebesar 0,441 artinya jika nilai variabel $\mathrm{X}$ (pelayanan) bernilai 0 maka nilai variabel Y (kepuasan) akan bernilai sebesar 0,441. Nilai koefesien (b) sebesar 0,860 artinya nilai variabel $\mathrm{X}$ (pelayanan) bernilai positif artinya jika variabel 
Albetris dan Fadil Iskandar, Analisis Pelayanan Terhadap Tingkat Kepuasan Mahasiswa Fakultas Ekonomi Universitas Batanghari Jambi (Studi pada Laboratorium Statistik Fakultas Ekonomi Universitas Batanghari Jambi)

pelayanan (X1) naik sebesar 1 satuan maka akan meningkatkan variabel Y (kepuasan) sebesar 0,860 dengan asumsi variabel lainnya tetap.

\section{Koefisien korelasi}

Hasil perhitungan SPSS 20 untuk melihat koefesien korelasi dapat dilihat pada tabel dibawah ini :

Tabel 3. Analisis Korelasi

Model Summary

\begin{tabular}{lrrrrr}
\hline Model & $\mathrm{R}$ & $\mathrm{R}$ Square & Adjusted R Square & \multicolumn{1}{c}{ Std. Error of the Estimate } & Durbin-Watson \\
\hline 1 &, $935^{\mathrm{a}}$ &, 874 &, 873 &, 21135 & 1,817 \\
\hline
\end{tabular}

a. Predictors: (Constant), pelayanan

b. Dependent Variable: kepuasan

Koefesien korelasi antara X1 (promosi), X2 (lokasi) terhadap Y (keputusan pembelian) adalah 0,717, artinya terdapat hubungan yang erat antara variabel $\mathrm{X} 1$ (promosi), X2 (lokasi) terhadap Y (keputusan pembelian). Dari hasil pengujian hipotesis maka diperoleh nilai (Detreminasi) atau r2 sebesar 0,514 dengan demikian hasil tersebut menyatakan bahwa variabel X1 (promosi), X2 (lokasi) mampu menjelaskan variabel Y (keputusan pembelian) sebesar 51,4\% sedangkan sisanya 48,6\% dipengaruhi oleh variabel lain yang tidak diteliti oleh penelitian ini.

\section{Koefisien korelasi}

Hasil perhitungan SPSS 20 untuk melihat koefesien determinasi dapat dilihat pada tabel dibawah ini :

Tabel 4. Analisis Determinasi

Model Summary ${ }^{b}$

\begin{tabular}{lrrrrr}
\hline Model & \multicolumn{1}{l}{ R } & R Square & Adjusted R Square & Std. Error of the Estimate & Durbin-Watson \\
\hline 1 &, $935^{\text {a }}$ &, 874 &, 873 &, 21135 & 1,817 \\
\hline
\end{tabular}

a. Predictors: (Constant), pelayanan

b. Dependent Variable: kepuasan

Koefesien korelasi antara X (pelayanan) terhadap $\mathrm{Y}$ (kepuasan) adalah 0,935 , artinya terdapat hubungan yang erat antara variabel $\mathrm{X}$ (pelayanan) terhadap $\mathrm{Y}$ (kepuasan).

Dari hasil pengujian hipotesis maka diperoleh nilai (Detreminasi) atau r2 sebesar 0,874 dengan demikian hasil tersebut menyatakan bahwa variabel $\mathrm{X}$ (Pelayanan) mampu menjelaskan variabel Y (Kepuasan) sebesar $87,4 \%$ sedangkan sisanya $12,6 \%$ dipengaruhi oleh variabel lain yang tidak diteliti oleh penelitian ini.

\section{Uji Hipotesis}

Hasil perhitungan SPSS 20 untuk melihat pengaruh antara variabel bebas dan variabel terikat dapat dilihat sebagai berikut :

Tabel 5. Hasil Analisi Uji F

\begin{tabular}{lllllll} 
& \multicolumn{5}{c}{ ANOVA $^{\mathbf{b}}$} \\
\hline Model & & Sum of Squares & Df & Mean Square & F & Sig. \\
\hline 1 & Regression & 13,442 & 2 & 6,721 & 51,249 &, $000^{\mathbf{a}}$ \\
& Residual & 12,721 & 97 &, 131 & & \\
Total & 26,162 & 99 & & & \\
\hline
\end{tabular}

a. Predictors: (Constant), pelayanan

b. Dependent Variable: Kepuasan

Berdasarkan Uji F menunjukkan bahwa hasil Fhitung adalah 51,249 sedangkan $\mathrm{F}$ tabel adalah sebesar 3,09. Dengan demikian bahwa penelitian tersebut dapat diterima karena Fhitung $>$ Ftabel.
Uji statistik $t$ digunakan untuk mengetahui pengaruh variabel independen $\mathrm{X}$ (pelayanan) mempengaruhi variabel dependen $\mathrm{Y}$ (kepuasan). Nilai $\mathrm{t}$ pada tabel dalam penelitian ini adalah 1,98472 (dengan melihat $\mathrm{t}$ tabel pada tingkat signifikansi 0,05 ).

Tabel 6. Uji t

Coefficients $^{\mathrm{a}}$

\begin{tabular}{|c|c|c|c|c|c|c|}
\hline \multicolumn{7}{|c|}{$\begin{array}{l}\text { Tabel 6. Uji t } \\
\text { Coefficients }^{\text {a }}\end{array}$} \\
\hline \multirow{2}{*}{\multicolumn{2}{|c|}{ Model }} & \multicolumn{2}{|c|}{ Unstandardized Coefficients } & \multicolumn{2}{|l|}{$\begin{array}{l}\text { Standardized } \\
\text { Coefficients }\end{array}$} & \multirow[b]{2}{*}{ Sig. } \\
\hline & & B & Std. Error & Beta & $\mathrm{T}$ & \\
\hline 1 & (Constant) &, 682 & 178 & & 3,831 &, 000 \\
\hline & Pelayanan &, 118 & ,104 & ,173 & 1,143 & ,256 \\
\hline
\end{tabular}

a. Dependent Variable: Kepuasan 
Hasil analisis uji $t$ adalah nilai $t$ hitung pada variabel $\mathrm{X}$ (pelayanan) adalah 1,143 dengan tingkat signifikansi 0,00 karena nilai t hitung $1,143<$ nilai $\mathrm{t}$ tabel 1,98472 dan tingkat signifikansi $0,256>$ probabilitas signifikansi $\alpha=0,05$, maka Ho diterima dan H1 ditolak. Hal ini berarti variabel Pelayanan secara individual berpengaruh terhadap keputusan pembelian.

\section{SIMPULAN}

Berdasarkan pembahasan pada bab sebelumnya maka dapat ditarik kesimpulan sebagai berikut :

1. pelayanan memiliki nilai rata- rata sebesar 439,1 , artinya pengguna jasa ( mahasiswa ) sangat puas terhadap pelayanan laboratorium komputer Fakultas Ekonomi Universitas Batanghari Jambi.

2. pengguna jasa ( mahasiswa) memiliki tingakat kepuasan yang sangat puas dalam pelayanan laboratorium komputer Fakultas Ekonomi Universitas Batanghari Jambi, dengan nilai rata rata sebesar 409,2.

3. Berdasarkan uji statistik diketahui bahwa terdapat pengaruh signifikan antara pelayanan terhadap kepuasan pengguna jasa ( mahasiswa) laboratorium komputer Fakultas Ekonomi Universitas Batanghari Jambi, dengan menggunakan uji $\mathrm{t}$ yaitu, $\mathrm{t}_{\text {hitung }}=26.106>\mathrm{t}_{\text {tabel }}=$ 1,984 maka keputusan $\mathrm{H} 0$ ditolak dan $\mathrm{H} 1$ diterima

\section{DAFTAR PUSTAKA}

Djarwanto, dan Subagyo, Pangestu, ((2000), Statistik Induktif, Edisi 4, BPFE, Yogyakarta

Fandy, Tjiptono. 2011. Strategi Bisnis dan Manajemen. Penerbit Andi, Yogyakarta

Handi, Irawan. (2002). 10 Prinsip Kepuasan Pelanggan. Jakarta : Elex Media. Komputindo

Husein Umar. 2000. "Metodologi Penelitian". Gramedia Pustaka Umum, Jakarta.

Kotler Philip, dan Gary Amstrong 2012. Principles Of Marketing, Global Edition, 14 Edition, Pearson Education

Lupiyoadi, Rambat. 2001. Manajemen Pemasaran Jasa. Salemba Empat. Jakarta.

Margono, Gaguk. 2005. Validitas Konstruk Instrumen Pengukur Tingkat Kepuasan Mahasiswa sebagai Pelanggan Internal. Jurnal PTM. Vol. 5. No. 1. 9 - 18.

Sekaran, U. 2006. Research Methods for Business. Penerbit Salemba. Jakarta. Hal 38

Supranto, J. 2006. Pengukuran Tingkat Kepuasan Pelanggan Untuk Menaikkan Pangsa Pasar. PT Rineka Cipta. Jakarta. Hal 97

Sugiyono. 2004. Statistika Untuk Penelitian. CV Alfabeta. Bandung. Hal 86

Tim PEKERTI-AA. 2007. Panduan Evaluasi Pembelajaran. Surakarta: UNS.

Widarti, Ari, I. A Eka Padmiari dan Ketuk Lilik Arwati. 2008. Tingkat Kepuasan Mahasiswa terhadap Proses Belajar Mengajar di Jurusan Gizi
POLTEKKES DEPKES Denpasar. Jurnal Skala

Husada. Vol.5. No.2. 163 - 167 